\title{
FISIOTERAPIA NA ESTRATÉGIA DE SAÚDE DA FAMÍLIA: PERCEPÇÃO DOS USUÁRIOS
}

\author{
PHYSIOTHERAPY IN FAMILY HEALTH STRATEGY: PERCEPTION OF USERS
}

\author{
Paulo Roberto Rocha Júnior ${ }^{\mathrm{a}}$ \\ Luciane Marquesini Moreirab \\ aprochajr@terra.com.br \\ bluluava.moreira@gmail.com \\ Universidade Paulista - Campus Assis (SP), Brasil
}

Data de recebimento do artigo: 12/11/2015

Data de aceite do artigo: 02/06/2016

\section{RESUMO}

Introduçáo e objetivo: Este estudo teve por objetivo analisar as percepçóes dos usuários sobre a ação da fisioterapia na Estratégia de Saúde da Família (ESF). Materiais e métodos: Participaram da pesquisa oito $(\mathrm{n}=8)$ indivíduos que haviam sido assistidos por um estágio de fisioterapia preventiva em ESF. Para a coleta de dados foram utilizadas entrevistas semidiretivas, em que emergiram as categorias de análise que ficaram assim divididas: "validando o fisioterapeuta na ESF" e "ponderaçôes do papel do fisioterapeuta na ESF: com a palavra, os usuários". Resultados e conclusão: Os usuários entrevistados são unânimes quanto à importância do fisioterapeuta em compor equipes da ESF, e que, ao fazê-lo, pode contribuir com seu saber para a qualificação da assistência.

Palavras-chave: Saúde da família; atenção primária à saúde; fisioterapia.

\section{ABSTRACT}

Introduction and objective: This study aimed to examine the perceptions of users about the action of physiotherapy in the Family Health Strategy (FHS). Materials and methods: Participated in the research eight $(\mathrm{n}=8)$ individuals that have been assisted by an internship in preventive physiotherapy in FHS. For data collection we used semi-directive interviews, in which the following categories of analysis emerged and were thus divided: "validating the physiotherapist in the FHS" and "considerations of the role of the physiotherapist in the FHS: with the word, the users". Results and conclusion: Users interviewed are unanimous about the importance of the physical therapist in composing ESF teams, and, in doing so, contribute with their knowledge to the quality of care.

Keywords: Family; primary health care; physiotherapy. 


\section{Introdução}

Entende-se por atenção básica $(\mathrm{AB})$ o conjunto de açóes, no âmbito individual e/ou coletivo, que abrange a promoçáo e a proteçáo da saúde, a prevenção de agravos, o diagnóstico, o tratamento, a reabilitação e a manutenção da saúde ${ }^{1,2}$. Para tanto, na expectativa de reorganizar os serviços de $\mathrm{AB}$, o Ministério da Saúde desenvolveu a Estratégia de Saúde da Família (ESF) ${ }^{2}$.

A ESF tem como ponto central o estabelecimento de vínculos e a criação de laços de compromisso e de corresponsabilidade entre os profissionais de saúde e a população. Essa estratégia apresenta princípios e diretrizes que se revelam contra-hegemônicos na lógica de organização de serviços e nas práticas de saúde, requerendo ações com enfoque sobre problemas, planejamento e programação local, com participação da sociedade civil e ênfase na intersetorialidade ${ }^{3}$.

A equipe mínima de saúde da família é composta por médico, enfermeiro, auxiliar de enfermagem e agente da saúde, podendo ser incorporados outros profissionais, de acordo com a demanda local, que deverá, antes de tudo, reordenar a $\mathrm{AB}$ em saúde .

Nesse contexto, um primeiro desafio que se apresenta para a implementaçáo da ESF é o de envolver os profissionais inseridos na estratégia em um amplo processo de reorientaçáo do trabalho em saúde. Essa nova lógica consiste em uma prática ativa e, ao contrário do modelo hegemônico, não está mais regulada pela produção, por números de consultas médicas e pela organização da oferta de serviços baseada na disponibilidade de equipamentos ou recursos humanos; enfim, é um modelo de atenção centrado nos interesses dos usuários ${ }^{4}$.

Assim, um segundo desafio diz respeito aos próprios usuários do serviço. O princípio da corresponsabilizaçáo e participação chama-o a tomar parte na produção de sua própria saúde, ou seja, ser ator de seu cuidado 5 .

Nesse cenário, o Ministério da Saúde lançou a portaria no 154 , de 24 de janeiro de 2008, que cria os Núcleos de Apoio à Saúde da Família (NASF). Essa portaria estabelece que esses núcleos sejam constituídos em equipes compostas de profissionais de diferentes áreas de conhecimento e que atuarão em parceria com os profissionais das ESF, compartilhando as práticas em saúde nos territórios sob responsabilidade das ESF, atuando diretamente no apoio às equipes e na unidade na qual o NASF está cadastrado ${ }^{2}$. Traz, ainda, no inciso II do artigo $3^{\circ}$, o rol desses profissionais, dos quais se destaca o fisioterapeuta, vinculando-o às ações de reabilitação, as quais define, no anexo I, como aquelas que propiciam a redução de incapacidades e deficiências, com vistas à melhoria da qualidade de vida dos indivíduos, favorecendo sua reinserção social, combatendo a discriminação e ampliando o acesso ao sistema de saúde ${ }^{2}$.

O fisioterapeuta pode desenvolver atividades efetivas em todos os níveis de atenção à saúde, dentro da equipe interdisciplinar. Porém, considerando aspectos de ordem político-econômicas e organizacionais, sua função é pouco divulgada e subutilizada. Contudo, paulatinamente, experiências isoladas em algumas regiôes brasileiras mostram que a inserção da fisioterapia na ESF enriquece e desenvolve ainda mais os cuidados de saúde da população ${ }^{6}$.

No ano de 2011, o curso de fisioterapia de uma universidade do interior de São Paulo implementou o estágio supervisionado de fisioterapia preventiva em $\mathrm{ESF}^{7}$ - proposta que tem como objetivo geral o desenvolvimento de ações de fisioterapia preventiva estritamente na $A B$. Todavia, o encontro de estudantes, profissionais e usuários é marcante para a compreensão das dimensões da produção do cuidado e para a produção de novas práticas ${ }^{8}$. É importante destacar que o projeto institucional não foi baseado em outro, em específico, e sim de uma disponibilidade de diversos atores em experimentar diferentes modalidades de intervençáo, bem como noutros lugares coletivos.

O projeto institucional ensejou não apenas o desejo em conhecer as possíveis relaçóes que se desenvolverão entre os atores, mas também a oportunidade, em específico, de verificar a aproximação dos fisioterapeutas e usuários.

Assim, a justificativa para esta pesquisa se baseia no fato de que mesmo estando orientado o papel do fisioterapeuta junto a ESF, faz-se necessário observar as percepçôes dos usuários sobre a nova situação, uma vez que o projeto terapêutico, seja individual ou coletivo, se dá também a partir do outro - nesse caso, o usuário.

\section{Materiais e métodos}

Este projeto de pesquisa tem como base um estudo qualitativo e descritivo sobre o entendimento dos usuários quanto ao papel do fisioterapeuta em uma unidade da ESF, sendo aprovado por um Comitê de Ética em Pesquisa sob o certificado de apresentação para apreciação ética no 02569412.3.0000.5512.

Participaram da pesquisa oito $(n=8)$ usuários de uma ESF do interior do estado de São Paulo, escolhidos aleatoriamente, de ambos os sexos e que haviam sido assistidos pelos alunos do estágio de fisioterapia preventiva em ESF. Todos aceitaram participar de forma voluntária, conforme o Termo de Consentimento Livre e Esclarecido. 
O número de participantes não foi baseado em nenhum critério estatístico. Os usuários no corpo da pesquisa foram identificados por letra e número, a fim de resguardar suas identidades.

Para a coleta de dados foram utilizadas entrevistas semidiretivas, assim chamadas por partirem de um roteiro e por procurar manter a margem de movimentação dos informantes táo amplas o quanto possível ${ }^{8}$. Dessa forma, o roteiro foi composto por seis temas: o primeiro referia-se ao contato com algum profissional de fisioterapia; o segundo tratava do grau de apropriação do seu estado de saúde à época do contato, bem como do conhecimento sobre o projeto terapêutico estabelecido; o terceiro e quarto diziam respeito ao conhecimento do processo de trabalho efetuado na ESF ao qual o informante pertencia; o quinto e sexto solicitavam análises da importância e do papel do fisioterapeuta na ESF.

As entrevistas foram gravadas, feitas individualmente e realizadas na totalidade na residência dos participantes, nos meses de fevereiro e março de 2013. Após a transcrição de cada entrevista, procedemos à leitura atenta de todos os transcritos, o que possibilitou reordenar as categorias de análise, que ficaram assim divididas: "validando o fisioterapeuta na ESF" e "ponderaçóes do papel do fisioterapeuta na ESF: com a palavra, os usuários".

$\mathrm{Na}$ análise de conteúdo, o texto é um meio de expressão do sujeito, no qual o analista busca categorizar as unidades que se repetem, conferindo uma expressáo que as represente?.

\section{Resultados}

Em relação à primeira categoria de análise, "validando o fisioterapeuta na ESF", observam-se três assertivas distintas para a justificativa de tal importância, apresentadas no Quadro 1.

$\mathrm{Na}$ categoria "ponderaçóes do papel do fisioterapeuta na ESF: com a palavra, os usuários", observamos também três assertivas (Quadro 2).

Quadro 1: Categoria de análise referente à "validando o fisioterapeuta na ESF".

\begin{tabular}{|c|c|}
\hline Assertiva & Falas \\
\hline $\begin{array}{c}\text { Ampliação dos cuidados/serviços } \\
\text { à população }\end{array}$ & $\begin{array}{c}\text { "Com certeza, e náo pelo caso de que agora eu tô precisando, mas tem várias gente que precisa, então, não } \\
\text { é só eu no momento, muitos precisam, tem vários que necessitam [...]" (U4). } \\
\text { "Seria sim porque ele taria vindo em casa, ensinando a gente a fazer os exercícios em casa, dando conti- } \\
\text { nuidade [...]” (U6). }\end{array}$ \\
\hline $\begin{array}{l}\text { Critério da territorialidade, ou } \\
\text { seja, da possibilidade de um } \\
\text { novo serviço no local em que } \\
\text { se vive }\end{array}$ & $\begin{array}{r}\text { "Eu acho. Porque quando a gente precisar, ai tem no postinho [risos] não é verdade? [risos] é mió te aí, } \\
\text { né? Senão tem de pagá” (U2). } \\
\text { "Já foi pedido há muito tempo, muitos anos atrás, é, eu me lembro... a gente até conversou, näo sei que } \\
\text { prefeito foi, não me lembro o nome dele agora” (U3). } \\
\text { "Ah! Se tivesse era uma bençâo, porque era... transporte, então se fosse aqui era melhor" (U7). }\end{array}$ \\
\hline $\begin{array}{l}\text { Saber próprio do fisioterapeuta } \\
\text { como elemento complementar } \\
\text { aos demais membros da equipe }\end{array}$ & $\begin{array}{l}\text { “Ah! Muito... ô louco, muito, porque é um conjunto, né, uma coisa puxa a outra, o médico, o } \\
\text { fisioterapeuta, a enfermeira... né, tem que tê. Eu achava que tinha de tê, no posto de saúde tinha que } \\
\text { ter tudo, complemento..." (U1). } \\
\text { “[...] com uma dor no ombro, com uma dor no quadril ou com dor no pescoço, o médico não sabe o que é que } \\
\text { é, somente o fisioterapeuta que tá treinado pra isso, pra isso ele estuda, por isso ele chama fisioterapeuta” (U3). }\end{array}$ \\
\hline
\end{tabular}

Fonte: Elaborado pelos autores.

Quadro 2: Categoria de análise referente às "ponderações do papel do fisioterapeuta na ESF: com a palavra, os usuários"

\begin{tabular}{|c|c|}
\hline Assertiva & Falas \\
\hline $\begin{array}{l}\text { Papel do fisioterapeuta vincula- } \\
\text { do às experiências anteriores do } \\
\text { usuário com a fisioterapia }\end{array}$ & $\begin{array}{c}\text { "[...] passava um ferrinho, passava um gel e passava o ferrinho e pegava e dava o choque, aquele choqui- } \\
\text { nho sabe? E... só isso que fazia. E a outra fazia exercício na cama" (U2). } \\
\text { "[...] eu tava muito debilitado e fraco, com os braços travando, é... é... atrofiando, fez bastante exercícios } \\
\text { com os braços e nas mãos e ajudou um pouco" (U4). } \\
\text { "[...] deu uma parada cardiorrespiratória, foi feito exercício de levantar braço, erguer a perna, mexer a } \\
\text { mão para não ficar atrofiado" (U6). }\end{array}$ \\
\hline
\end{tabular}


Quadro 2: Continuação.

\begin{tabular}{|c|c|}
\hline Assertiva & Falas \\
\hline $\begin{array}{l}\text { Papel orientador do } \\
\text { fisioterapeuta }\end{array}$ & $\begin{array}{r}\text { "[...] seria muito importante, ensinar as pessoas da casa a fazer os exercícios, pra pessoa não ir atrofiando, } \\
\text { principalmente quem é acamado" (U6). } \\
\text { "[...] ensinar a gente a fazer os exercícios que precisa necessário, prá gente voltar a ter, como é que se diz?? } \\
\text { O reflexo certo dos movimentos, né?" (U4). }\end{array}$ \\
\hline $\begin{array}{l}\text { Visita domiciliar enquanto } \\
\text { ferramenta de trabalho para o } \\
\text { fisioterapeuta, concedendo a ele } \\
\text { um aspecto de proativo }\end{array}$ & $\begin{array}{r}\text { "[...] Olha... têm muitos causos, muita gente que não pode... não pode saí do local, é o causo meu, eu } \\
\text { dependo de um táxi, então não é todo dia que a gente... tá com dinheiro e pra pagar o táxi ida e volta, } \\
\text { tudo... no causo meu se eu fosse pagar um táxi, pra ir fazer, então fica muito caro, vai o ordenado tudo, } \\
\text { então o fisioterapeuta se ele viesse na casa, melhor ainda" (U1). } \\
\text { "[...] vir ver a gente, ver o que tá certo, ensinar" (U5). } \\
\text { "[...] ah... eu não... nấo sei... se teria que fazer uma visita uma vez por semana e orientar bem a pessoa, } \\
\text { né... eu penso assim" (U9). }\end{array}$ \\
\hline
\end{tabular}

\section{Discussão}

O Sistema Único de Saúde tem apresentado resultados positivos quanto aos propósitos de universalização, descentralização e ampliação de cobertura dos serviços de saúde. Porém, avança com mais dificuldade na garantia da qualidade, equidade e na resolutividade da assistência ambulatorial e hospitalar, principalmente pela falta de profissionais habilitados a prestar assistência integral de saúde ${ }^{10}$.

Ribeiro ${ }^{11}$ coloca em pauta que a inserção do fisioterapeuta nos serviços de $\mathrm{AB}$ é um processo em construção, associado principalmente à criação da profissão, rotulando o fisioterapeuta como reabilitador, voltando-se apenas para uma pequena parte de seu objeto de trabalho, que é tratar a doença e suas sequelas. Durante muito tempo essa lógica de conceitualização excluiu da rede básica os serviços de fisioterapia, causando uma grande dificuldade de acesso da população a esse serviço e impedindo o profissional de atuar na atenção primária.

Dessa forma a proposta institucional de estágio supervisionado de fisioterapia preventiva em ESF não só possibilita novos campos de estágios para o aluno do curso como - e sobretudo - inaugura o acesso dos usuários a esse serviço.

Outro fato evidenciado e que diz respeito à prática propriamente dita da fisioterapia na $\mathrm{AB}$ foi o de que as expectativas dos usuários estão vinculadas a experiências pregressas, construídas em atendimentos em outros níveis de atenção que não o da $\mathrm{AB}$. Nesse contexto, verifica-se a importância da inserção do profissional fisioterapeuta como agente multiplicador de saúde, desenvolvendo suas atividades em interaçáo com uma equipe multiprofissional e de forma interdisciplinar ${ }^{12}$.

Assim, mais do que ponderar atribuiçóes especificas, é importante salientar que a $\mathrm{AB}$ prevê a resolutividade das necessidades de saúde que extrapolam a esfera de intervenção curativa e reabilitadora individual, por meio da promoção da saúde, prevenção de doenças e educaçáo continuada ${ }^{13}$.
Mais uma vez fica posto o caráter inaugural do estágio supervisionado de fisioterapia preventiva em ESF pelo fato de propiciar ao aluno não só o conhecimento da doença e de formas de intervenção, mas, principalmente, o contato com o indivíduo no domicílio, na família e na comunidade e, a partir disso - e com visão crítica e reflexiva - ser capaz de produzir uma prática, um cuidado individual ou coletivo, na perspectiva da integralidade e, dessa forma, construir coletivamente o seu papel.

\section{Conclusão}

Com esta pesquisa foi possível concluir que os usuários entrevistados são unânimes quanto à importância de o fisioterapeuta compor equipes da ESF e que, ao fazê-lo, pode contribuir com seu saber para melhorar a qualidade da assistência.

\section{Referências}

1. Brasil. Ministério da Saúde. Portaria no 4.279, de 30 de dezembro de 2010. Estabelece diretrizes para a organização da Rede de Atenção à Saúde no âmbito do Sistema Único de Saúde (SUS). Brasília: Diário Oficial da União; 2010.

2. Brasil. Ministério da Saúde. Portaria GM no 154, de 24 de janeiro de 2008. Cria os Núcleos de Apoio à Saúde da Família - NASF. Brasília: Diário Oficial da União; 2008.

3. Rocha AARM, Trad LAB. A trajetória profissional de cinco médicos do Programa Saúde da família: os desafios de construção de uma nova prática. Interface Comum Saúde Educ. 2005;9(17):303-16.

4. Brasil. Ministério da Saúde. Portaria no 1.886 , de 18 de dezembro de 1997. Aprova as Normas e Diretrizes do Programa de Agentes Comunitários de Saúde e do Programa de Saúde da Família [Internet]. 1997 [citado em 2013 maio 16] Disponível em: http://189.28.128.100/dab/docs/legislacao/portaria1886_18_12_97.pdf 
5. Brasil. Ministério da Saúde. Portaria no 493, de 13 de março de 2006. Aprova a relação de indicadores da Atenção Básica - 2006, cujos indicadores deveráo ser pactuados entre municípios, estados e Ministério da Saúde [Internet]. 2006. [citado em 2013 maio 5]. Disponível em: http://www.agu. gov.br/atos/detalhe/17646

6. Brasil ACO, Brandão JAM, Silva MON, Gondim Filho VC. O papel do fisioterapeuta do Programa de Saúde da Família do município de Sobral - Ceará. Rev Bras Prom Saúde. 2005;18(1):3-6.

7. Rocha Júnior PR. Estágio supervisionado de fisioterapia em Estratégia de Saúde da Família [projeto institucional]. Assis: Departamento de Fisioterapia, Universidade Paulista; 2011.

8. Minayo MCS. O desafio do conhecimento: pesquisa qualitativa em saúde. São Paulo: Hucitec; 1996.
9. Caregnato RCA, Mutti R. Pesquisa qualitativa: análise de discurso versus análise de conteúdo. Texto \& contexto enferm. 2006;15(4):679-84.

10. Baduy RS, Oliveira MSM. Polos de formação, capacitação e educação permanente para os profissionais das equipes de Saúde da Família: reflexos a partir da prática no Polo Paraná. Olho Mágico. 2001;8(2):17-20.

11. Ribeiro KSQ. A atuação da fisioterapia na atenção primária à saúde. Fisioter Bras. 2002;3(5):311-8.

12. Ragasson CAP, Almeida DCS, Comparin K, Mischiati MF, Gomes JT. Atribuiçôes do fisioterapeuta no programa de saúde da família: reflexóes a partir da prática profissional. Olho Mágico. 2006;13(2):1-8.

13. Paim JS, Naomar AF. Saúde Coletiva: uma nova saúde pública ou campo aberto a novos paradigmas? Rev Saúde Pública. 1998;32(4):299-316.

\section{Como citar este artigo:}

Rocha Júnior PR, Moreira LM. Fisioterapia na estratégia de saúde da família: percepção dos usuários. Rev. Aten. Saúde. 2016. Rev. Aten. Saúde. 2016;14(50):21-25. 